naturaleza o se lo hacen tomar, desnaturalizándolo, o se desinteresan de la cuestión y proceden guiados solo por vagas impresiones del momento.

Seguramente a un industrial de tejidos, por ejemplo, no se le ocurrirá consultar para un asunto técnico de su industria a un albañil, a un chofer, a un abogado, a un médico o a un dentista, sino que se dirigirá a los que por sus conocimientos sean capaces de resolver efectivamente el problema. Igual cosa hará a su vez el albañil para sus asuntos; el abogado para los suyos; y lo mismo el comerciante o el banquero. Nadie querrá exponer su negocio o industria con la intervención de los profanos a ella. Pues bien, este sistema que nadie quiere aplicar a sus negocios propios se aplica de preferencia en los grandes problemas del Estado. En un reciente debate de nuestra Cámara acerca de un tratado que afecta a la industria agrícola se pudo ver claramente este defecto fundamental en un breve episodio de la discusión. Hablaba un Diputado agricultor y fué interrumpido por una observación que posiblemente no tenía valor desde el punto de vista técnico. El orador interrumpido contestó a ella con una interrogacción: ¿el H. Diputado es profesional? Esa sencilla interrogación cae sobre el verdadero punto débil del sistema parlamentario actual.

Así ocurre que, dentro de este sistema, en un problema agrícola intervienen personas de muý distinta preparación en el asunto y todos sus votos valen igualmente. Lo mismo pasa en cualquiera otra materia, la educacional, por ejemplo, en la que las opiniones de los profesores tienen el mismo valor que la de los agricultores, ingenieros o médicos y aun de personas que no han frecuentado en su juventud los Liceos ni las Universidades Fácil es comprender y aun palpar en la vida diaria los graves inconvenientes que resultan de este hecho el cual ha contribuído, sin duda en mucha parte, a quitar al sistema parlamentario su antiguo prestigio.

Para este grave mal, la democracia liberal no tiene remedio alguno, pues para ello tendría que cambiar las bases de la organización del legislativo y transformar el parlamento en una Cámara gremial. - L U I D . CR U Z O C A P O.

\title{
LOS HOMBRES COMO SIMBOLOS
}

\section{RiCARDO JAIMES FREYRE}

TEPHAN ZwEIG habría buscado para su vasta tipología del espíritu, donde se alean las fuerzas distintas y enérgicas de 
la personalidad, esta figura singular y aristocrática de Ricardo Jaimes Freyre, gran señor de las letras americanas.

Y la habría buscado porque en el desaparecido autor de "Castalia Bárbara», confluyen justamente aquellas calidades eminentes del individuo que, como en un poderoso bajo relieve, destacan al hombre sobre la masa oscura de las muchedumbres.

Más allá del estadista, de las finas y sutiles mallas de la diplomacia, del vaso armonioso de los versos o del austero evangelio de la enseñanza, tocamos la secreta virtud de este privilegiado espíritu, que siendo orador, parlamentario, poeta, historiador, plenipotenciario, periodista, político y maestro, afirmó todos los minutos el señorío de su recia personalidad en el universo activo de la sociedad.

Así los hombres del Renacimiento, desbordantes de savia vital, tallaban cada día la soberbia escultura dél individuo: compartiendo en el tiempo aptitudes, agotando el caudal de las humanas tentativas, enriqueciéndose por la experiencia y llevando el ejercicio del ser a los más opuestos extremos.

Aquella constante de energía, que es el distintivo más eficaz del siglo $\mathrm{XV}$, brind 6 a la humanidad totalidades tan excelsas como las de Lorenzo el Magnífico, diplómata, músico, príncipe, banquero, poeta y comerciante; Miguel Angel, maestro de escultores y pintores, estratega, poeta e ingeniero militar; el Papa Julio II, tenaz y ardido defensor de la unidad italiana, estadista, consumado político, notable animador de las artes; Macchiavello, servidor de príncipes, político activísimo, filósofo escéptico, consejero de Estado de César Borgia e historiador de aguda mirada. Y sobrepasando la estatura desmedida de sus contemporáneos, el genio de Leonardo, que es el genio del Renacimiento, abarcando todas las artes, invadiendo todas las ciencias, arrancando secretos a la naturaleza, anticipando portentosos descubrimientos científicos, preparando la gran levadura para que dos siglos más tarde la Europa concentrara en Goethe el espíritu máximo de la cultura occidental.

Distante del genio renacentista; distante también del escenario fastuoso y magnífico donde se movieron sus radiantes expresiones individuales, el hombre del siglo $\mathrm{XX}$, urgido por el vértigo de una civilización que hinca en la celeridad sus raíces, reducido en todas sus vivencias por las inmensas marejadas de la multitud, que quiere humillarlo para imponerle la absurda y tremenda ley de su uniformidad, sólo puede actuar en función de símbolo para realizar al individuo. Como Cunninghame Graham, el nuevo Quijote de la vieja Europa, cuyas virtudes inactuales 
hacen de su figura y de su obra una valencia simbólicafantes que una realidad viviente.

¿Cómo no hablar, entonces, de esos valores simbólicos quie sobre las fauces negras de la sima, ponen el resplandor fugaz de su energía y de su noble orgullo humano? Despojados del prestigio pretérito, lejos del fondo luminoso de los antiguos horizontes, ausentes de sus vidas, pompa y esplendor, estos últimos sobrevivientes en el vasto naufragio de la conciencia individual, se afirman estoicamente sobre su inmediata y trágica verdad. Para afrontar los peligros y desafiar a las grandes masas monótonas que se rebelan, desconociendo las leyes que fraguaron el ser.

El genio poético de Ricardo Jaimes Freyre, vibra en la polífona armonía de "Castalia Bárbara», "Los Sueños son Vida», «La Hija de Jefhté» y "Los Conquistadores»; la noble y sobria belleza de su prosa en "Historia del Tucumán Colonial», «His-toria de la Edad Media y de los Tiempos Modernos», «Aspectos del Brasil» y otros trabajos que le conceden ejecutoria para figurar entre los escritores sobresalientes de habla hispana.

Mas el hombre, ¿dónde está el hombre? ¿Dónde el espíritu que resistiendo el análisis proustiano, pudiera decir: yo soy el hombre? El hombre es, justamente, la virtud más eminente del poeta desaparecido.

Doble sabiduría, su ambición persigue realizar armoniosamente al hombre de acción con el hombre de pensamiento. Eterna y profunda fórmula que expresa el secreto poderío en la historia del individuo y mediante la cual Jaimes Freyre será estadista en su patria, poeta en la América, hombre de mundo en el esplendor de los salones o en el remolino brusco de las rúas.

Desde la bohemia vaciada en rebeldías con que hizo su aparición è modernismo en la América sureña; junto a Darío y a Lugones, aventajándole en genio poético el primero para ceder ambos en personalidad al boliviano; o en las polémicas fogosas que registraba "La Revista de América», donde todos tres lucharon con denuedo por el remozamiento estético del continente, afirmó invariablemente una enérgica voluntad que repudiaba el oro trémulo de los licores, una clara conciencia hendida por el arte y el conocimiento; y aquella señorial aristocracia que jamás perdonaron los sicofantes enardecidos de la sociedad o de las letras, pero respetada y comprendida siempre donde la nobleza de alma preside la convivencia humana.

El hombre, en Jaimes Freyre, es la indomable energía que tallo los versos impecables de «Castalia Bárbara». Es la búsqueda insatisfecha de la perfección estética, que colmo sus horas con 
amargas ansiedades para darle después la miel dorada de los éxitos finales. $\mathrm{O}$ el deseo tenaz que conmueve las fuerzas oscuras del espíritu; hondo y sagrado deseo de alcanzar la verdad que para Lessing es más satisfactorio que la verdad misma.

Vasto en espíritu, el hombre, en Jaimes Freyre, tuvo singulares condiciones físicas.

Mediana la estatura. Erguido el torso varonil. Alta la frente. Señorial el porte. De rasgos firmes y duros el rostro; apretada la piel; cruzados de vivacidad y altaneros los ojos. Decorando la imponencia del rostro, el escorzo atrevido de los mostachos mosqueteriles. Y luego el clásico chambergo alado voluntariosamente curvado sobre la rebelde y crinada melena. Solemne el gesto, la voz sonora y grave, fluían las palabras con majestad y cuando el orador ocupaba la tribuna, toda la arquitectura humana se sacudía al imperio de una eléctrica fuerza y dotaba al hombre de notable poder persuasivo, cuando no suspendía la atención del auditorio con el rasgo violento de la diestra nerviosa o la fiebre iracunda de los ojos ardidos.

Ministro de Bolivia en Washington, donde el numeroso cuerpo diplomático opaca la actuación de los representantes sudamericanos y en especial de las pequeñas repúblicas, Jaimes Freyre impone rápidamente la severa arrogancia de su porte. Alguna vez en que, respetando los rígidos formulismos del protocolo, se hallen reunidos los ministros de diversas potencias, esperando pacientemente el momento de su ingreso al recinto de la Casa Blanca, descenderá el plenipotenciario boliviano de su automóvil, y ante la estupefacción de colegas y asistentes, cruzará marcialmente sobre el pavimento, dará un manotón al cordón que impedía la entrada y con gesto decisivo y voz airada dirá: «El Ministro de Bolivia no hace antesala para nadie».

Pero este gran señor de las airadas y definitivas actitudes, tiene también el orgullo de todas las conciencias superiores. Y si ayer tuvo la entereza suficiente para honrar su elevada investidura, tendrá mañana, al desempeñar la plenipotencia en Río de Janeiro, el orgullo y la dignidad suficientes para rechazar una advertencia del mandatario de su patria y enviarle junto con la renuncia de su cargo un cable altanero desconociéndole todo derecho de amonestación. Canciller de la república, durante el gobierno del Dr. Saavedra, en 1923, planteará resueltamente la revisión del Tratado de 1904 . Parlamentario, sostendrá encendidos debates. Político o diplomático, maestro, poeta u hombre de mundo, estará siempre erguido en su natural distinción, revestido de aquella fría y segura serenidad que le permitió afrontar desdeñosamente situaciones y obstáculos. 
El fondo más humano y patético de Jaimes Freyre, descansa en el noble e ilimitado amor que tenía por los suyos. Aquella íntima y profunda ternura familiar que prestigia singularmente la bondad secreta de su espíritu.

Alejado largos lapsos del escenario político y social de su patria, buscó en la Argentina asilos temporales que le fueron generosamente brindados. Presidente del Departamento de Educación en Tucumán, escribió allí su famosa y meritoria obra histórica que le valiera un importante premio. Muchos años más tarde, cuando despertando de sus éxtasis fugaces la aguja del destino marc 6 amargos sinsabores para el ilustre y voluntario exilado, Tucumán acudió noblemente en su ayuda, pagando una deuda de gratitud an taño contraída.

Austero para recibir las mercedes de la vida, es igualmente digno en soportar sus rigores. Así el príncipe de las letras americanas en la aurora del modernismo, tiene el orgullo capaz de ocultar la miseria final de su existencia, porque la aristocracia de su espíritu otorga la limosna, pero no solicita la dádiva.

$Y$ una noche de Abril, sola en el centro del mundo, la carne vacilante deja evadir el alma radiosa y triunfal de este gran americano, que al enseñarnos las eternas virtudes del individuo, sin jamás perder el sentimiento de la propia dignidad, tuvo la sabiduría de encontrar un sentido estético a su vida, para dar calidades perdurables a su obra y a su nombre, donde la personalidad, por múltiple y brillante, es un símbolo de aquel Renacimiento que parece alejarse cada vez mayormente de los hombres. $-F$ E R A N D O D I E Z D E M E D I N A .

La Paz-Bolivia-1933.

(Especial para Atenea).

\section{EL MATERIALISMO HISTORICO Y LA ETNO- GRAFIA MODERNA}

\section{(Continuación)}

OLAMENTE en ciertas ocasiones, como la de una caza comunal, en que toman parte todos los hombres hábiles, hay una repartición equitativa de lo producido por todos en conjunto y como en las grandes reuniones y fiestas comunales, a las cuales asisten todos los parientes $y$ en que todos aportan su 